Review article

\title{
Importance of integrons in the diffusion of resistance
}

\author{
Alessandra CARATTOLI* \\ Laboratory of Bacteriology and Medical Mycology, Istituto Superiore di Sanità, \\ v.le Regina Elena 299, 00161 Rome, Italy
}

(Received 23 November 2000; accepted 5 February 2001)

\begin{abstract}
Summary - Horizontal transfer of resistance genes is a successful mechanism for the transmission and dissemination of multiple drug resistance among bacterial pathogens. The impact of horizontally transmitted genetic determinants in the evolution of resistance is particularly evident when resistance genes are physically associated in clusters and transferred en bloc to the recipient cell. Recent advances in the molecular characterisation of antibiotic resistance mechanisms have highlighted the existence of genetic structures, called integrons, involved in the acquisition of resistance genes. These DNA elements have frequently been reported in multi-drug resistant strains isolated from animals and humans, and are located either on the bacterial chromosome or on broad-host-range plasmids. The role of integrons in the development of multiple resistance relies on their unique capacity to cluster and express drug resistance genes. Moreover, the spread of resistance genes among different replicons and their exchange between plasmid and bacterial chromosome are facilitated by the integration of integrons into transposable elements. The association of a highly efficient gene capture and expression system, together with the capacity for vertical and horizontal transmission of resistance genes represents a powerful weapon used by bacteria to combat the assault of antibiotics.
\end{abstract}

antimicrobial resistance / integron / transposon / horizontal gene transfer

Résumé - Importance des intégrons dans la diffusion de la résistance. Le transfert horizontal de gènes est un mécanisme efficace pour la transmission et la dissémination, parmi les agents pathogènes bactériens, de résistances multiples aux antibiotiques. L'impact des déterminants génétiques transmis horizontalement dans l'évolution de la résistance est particulièrement évident lorsque les gènes de résistance sont physiquement regroupés, et transférés en bloc à la cellule réceptrice. Des avancées récentes dans la caractérisation moléculaire des mécanismes de résistance aux antibiotiques ont mis en évidence l'existence de structures génétiques, appelées intégrons, impliqués dans l'acquisition de gènes de résistance. Ces éléments d'ADN ont été fréquemment observés dans des souches bactériennes multi-résistantes isolées chez des animaux ou chez des humains, localisés soit sur le chromosome bactérien, soit sur des plasmides à large spectre d'hôte. Le rôle des intégrons dans le développement de la multi-résistance repose sur leur capacité unique à former des clusters de gènes et à exprimer des gènes

* Correspondence and reprints

Tel.: (39) 06 49903128; fax: (39) 06 49387112; e-mail: alecara@ iss.it 
de résistance. De plus, la propagation des gènes de résistance parmi différents réplicons, et leur échange entre plasmides et chromosome bactérien sont facilités par l'intégration des intégrons dans des éléments transposables. L'association entre des systèmes extrêmement efficaces de capture et d'expression de gènes, et la capacité de transmission verticale et horizontale de gènes de résistance, représente une arme puissante utilisée par les bactéries pour combattre l'offensive des antibiotiques.

résistance antimicrobienne / intégron / transposon / transfert horizontal de gène

Table of contents

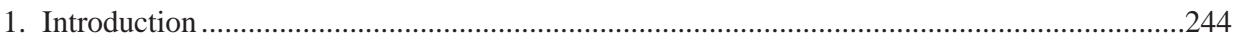

2. Horizontal gene transfer and integrons: evolution of antibiotic resistance .............................245

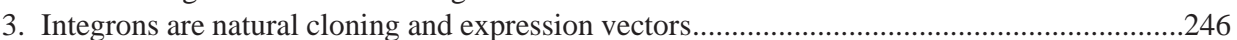

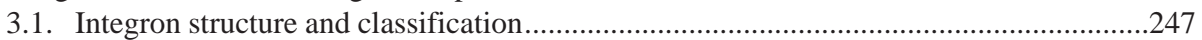

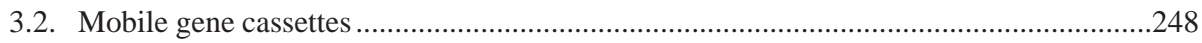

3.3. Site-specific insertion of gene cassettes in the integron .................................................249

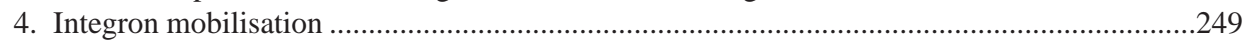

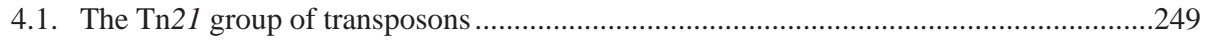

4.2. Clustering of resistance genes: is multi-drug resistance encoded on antibiotic

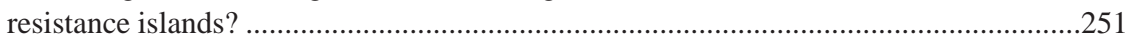

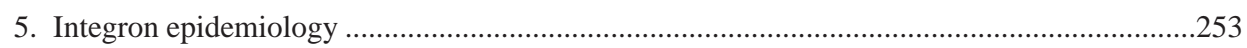

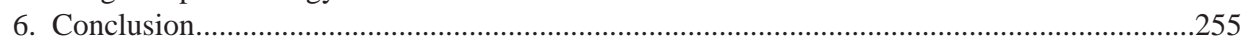

\section{INTRODUCTION}

During the past 20 years a significant amount of information related to the mechanism and spread of antibiotic resistance has become available. Investigation of the evolution of antibiotic resistance has been focused primarily on the clonal transmission of resistance traits originating from the sequential modification of pre-existing genes through the accumulation of point mutations. More recently, the impact of horizontally transmitted genetic determinants and the role of recombination in the recruitment of resistance genes have been highlighted [30, 52, 66].

Resistance genes can be exchanged among bacterial populations [24]. Several mechanisms for the acquisition and dissemination of resistance determinants involve DNA exchange and in this way resistance genes can spread efficiently among bacterial populations from animals and humans [28].
The identification of specialised genetic structures responsible for the acquisition of resistance genes on horizontal gene vehicles represents an important discovery in our understanding of antibiotic resistance mechanisms. Naturally occurring gene expression elements, called integrons, have been described as a very efficient genetic mechanism by which bacteria can acquire resistance genes [40, 56, 84]. Integrons promote the capture of one or more gene cassettes within the same attachment site, thereby forming composite clusters of antibiotic resistance genes.

Over the past few years, the analysis of many antibiotic resistance genes identified in clinical and veterinary isolates of Gramnegative organisms (particularly Enterobacteriaceae) established the importance of integrons in the dissemination of resistance among bacterial pathogens from different geographical origins. 


\section{HORIZONTAL GENE TRANSFER AND INTEGRONS: EVOLUTION OF ANTIBIOTIC RESISTANCE}

Antibiotic resistance is the best known example of rapid adaptation of bacteria to a new ecosystem. The ability of bacteria to expand their ecological niche, also in the presence of certain antibiotics, can be explained by the acquisition of resistance genes by horizontal gene transfer and/or by the accumulation of point mutations leading to the modification of existing genes. Several studies on bacterial pathogens of human and animal origin concluded that multiple antibiotic resistance is a consequence of horizontal gene transfer [87, 93].

The principal mechanisms facilitating horizontal gene transfer among bacteria are transformation, transduction and conjugation. Transformation involves the uptake and incorporation of naked DNA, which may become available in the environment following bacterial autolysis. This source of genetic material can be incorporated by naturally transformable bacteria, and by bacteria which become competent for transformation under special chemical or physical conditions [4, 29].

Exogenous DNA carried by phage particles can also be transferred to recipient bacteria by transduction. The bacteriophagemediated transfer of resistance genes would appear to be an uncommon mechanism as the transduction process is normally limited in host range, sometimes restricted to single bacterial clones [29].

Conjugation is the most frequently recognised mechanism for horizontal gene transfer. This mechanism exists in a wide variety of bacterial species and genera. In this process, mobilisable DNA molecules (plasmids, episomes, conjugative transposons) can be transferred from a donor to a recipient cell, via a contact-dependent transmission. The self-transmissible conjugative F-plasmid of Escherichia coli is the best-known example of an autonomously replicating molecule, which encodes all necessary factors required for conjugation. Some non-self-transmissible plasmids can also be mobilised in trans by an associated self-transmissible plasmid, which is not normally transferred at the same time. Conjugation can also mediate chromosomal exchange following the integration of a self-transmissible plasmid into the bacterial chromosome. Finally, conjugation can be promoted by conjugative transposons, which are mobile DNA elements encoding essential proteins required for the excision and transmission of the element into a recipient strain [29].

Once it has entered the recipient cell, the persistence of foreign DNA is required for horizontal transfer to be successful. In fact, DNA molecules lacking autonomous replication are lost unless integrated into the host chromosome or in another replicon by homologous or illegitimate recombination. Furthermore, DNA restriction systems that limit the uptake of foreign DNA exist. These systems have been described in several bacterial species, and can rapidly cleave incoming foreign DNA. Nevertheless, bacteriophages and conjugative plasmids have evolved evasion protocols to ensure survival in the new host. Examples of these defensive-mechanisms include reducing the number of restriction target sites or encoding antirestriction systems (e.g. methylation systems) $[5,9,14,97]$.

It is evident that when the newly acquired DNA molecule encodes for a selectable function, a positive selection benefits the host cell and would be expected to avoid stochastic loss of the episome or the inactivation by mutation of the foreign gene.

Horizontal transfer of antibiotic resistance genes provides a potentially saving ecological impact on any bacterial population exposed to an antibiotic treatment. However, the transferred resistance gene must be expressed in a manner that benefits the recipient microorganism.

Therefore how are antibiotic resistance genes incorporated into and expressed on a 
horizontally transferred DNA vehicle (i.e., a conjugative plasmid)?

Many recent investigations on the molecular basis for antibiotic resistance have highlighted the link between resistance determinants embedded in units of DNA called integrons and broad-host range plasmids [84]. This novel class of specialised DNA elements was initially described mainly from comparisons of the DNA sequence surrounding different antibiotic resistance genes found in naturally occurring Gram-negative bacteria. Early attempts to describe integrons suggested that they consisted of two conserved regions flanking a variable region containing one resistance gene or more [84]. A more detailed description of their structure established the existence of an attachment site recognised by a site-specific recombinase, the integrase, encoded by the integron. It is at this site that (an) antibiotic resistance gene(s) or any open reading frame (ORF) containing a particular recombination site can be incorporated and converted into a functional gene. In fact, integrons incorporate promoterless gene cassettes under the transcriptional control of a strong promoter, guaranteeing expression of the integrated genes. Integrons have a unique capacity to cluster resistance genes into complex operons, which can be expressed and disseminated by horizontal gene transfer.

\section{INTEGRONS ARE NATURAL CLONING AND EXPRESSION VECTORS}

Integrons are gene expression systems that incorporate ORFs and convert them into functional genes. The essential components of an integron include the integrase gene (intI), the attachment site (attI) and the promoter, which promotes the expression of any suitably integrated gene(s) (Fig. 1).

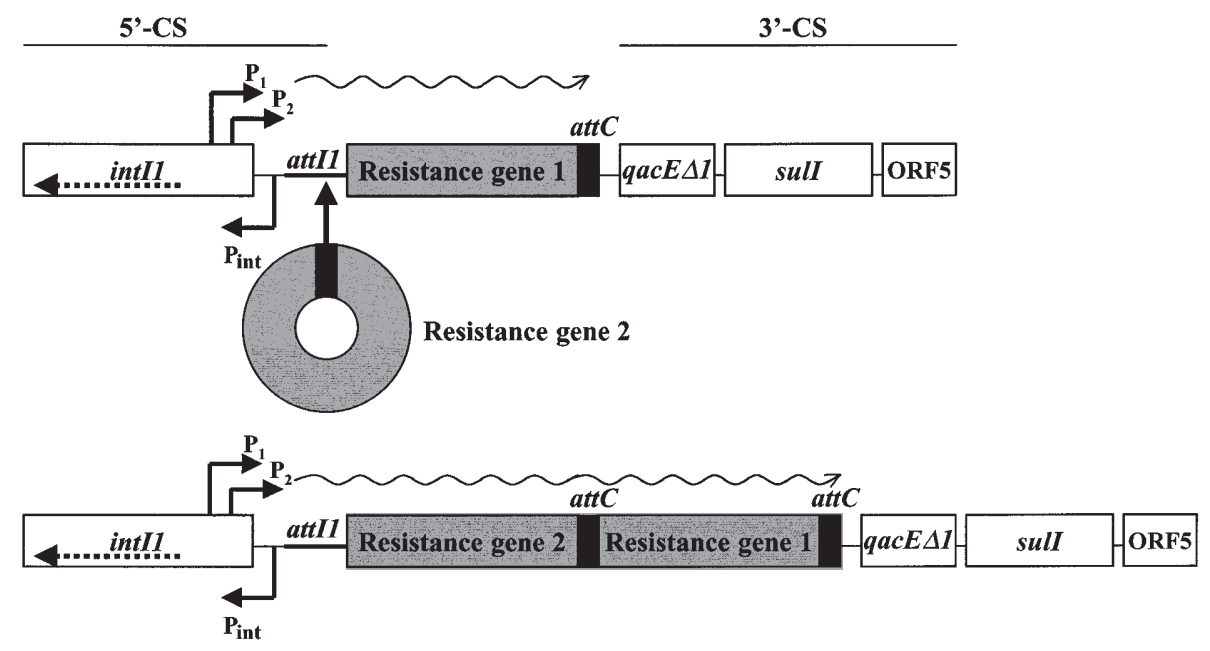

Figure 1. Schematic representation of a class 1 integron and a model for gene cassette acquisition. The process by which a circularised gene cassette (resistance gene 2) is inserted at the attI site in a class 1 integron containing a resident gene cassette (resistance gene 1) is outlined in the figure. Genes and open reading frames in the 5'- and 3'-CS of a schematic class 1 integron are indicated by boxes. Resistance gene cassettes inserted within the integron are indicated by grey boxes and vertical black bars represent att $C$ recombination sites. $\mathrm{P}_{1}$ and $\mathrm{P}_{2}$ are integron-associated promoters; $\mathrm{P}_{\text {int }}$ is the integrase gene (intII) promoter. The qacE $\Delta l$ and sulI genes in the 3'-CS confer resistance to quaternary ammonium compounds and sulfonamides, respectively. 
Integrase (IntI) is a member of the tyrosine site-specific recombinase family, which also includes the well-known $\lambda$-phage integrase. These enzymes catalyse the excision and integration of DNA units, by performing two consecutive strand breakage and rejoining steps. These steps take place without DNA synthesis or the intervention of high-energy cofactors (such as ATP). This conservative feature distinguishes sitespecific recombination from transposition, in which a repair synthesis step is required. Integrase is not a nuclease and its activity can be assimilated to that of a topoisomerase [48].

\subsection{Integron structure and classification}

Four classes of integron have been defined based on the homology of the integrase proteins (40-60\% amino acid identity).

Class 1 represents the most common structure and most of the elements belonging to this class are characterised by the presence of two conserved segments, the 5' -conserved segment (5'-CS) and 3'-conserved segment (3'-CS). The 5'-CS contains the intI gene, the attI site and the promoter, while the 3'-CS codes for the sull gene, conferring resistance to sulphonamides and the qacE $\Delta 1$ gene, conferring resistance to quaternary ammonium compounds used as disinfectants [73, 76, 84]. In addition, the 3'-CS carries the ORF5 encoding a protein of unknown function (see Fig. 1).

Antibiotic resistance gene cassettes are integrated between the 5' - and 3'-CS at the receptor attIl site. The integron designated In 0 contains no inserted genes, making the 5'- and 3'-CS regions adjacent to each other [6]. As many as seven different gene cassettes have been described within a single class 1 integron and more than 60 different resistance-gene cassettes have been identified to date [59]. More than one class 1 inte- gron has been observed within the same bacterial cell [91].

Class 2 integrons have also been described and these are included in the Tn7 family of transposons [40, 73]. Tn7 contains three integrated gene cassettes ( $d h f r I-$ sat-aadAl) adjacent to a defective integrase gene (intI2) located at 5'-CS. The Tn7 attI site is located between the intI2 gene and the first inserted resistance gene as described for class 1 integrons. Class 2 integrons do not contain the sull gene but in fact include genes whose function promotes $\mathrm{Tn} 7$ transposition [36, 72, 73, 88].

To date, only one class 3 integron has been reported, containing the $b l a_{\text {IMP }}$ gene cassette that confers resistance to broadspectrum $\beta$-lactams including carbapenems, and part of the aacA4 gene, previously identified as a gene cassette in class 1 integrons. The integrase gene (intI3) demonstrated an identity of $60.9 \%$ to the intIl gene at the amino acid level, with the gene cassette boundaries showing atypical recombination sites [2].

It is noteworthy that despite the differences in the integrase and attI site sequences, the same gene cassettes are thought to be acquired by all three integron classes, as identical gene cassettes have been found in classes 1 and $2[40,88]$ and in classes 1 and $3[2,49]$. This observation suggests that the class-specific integrases work on an apparently common pool of resistance gene cassettes.

A fourth class of integron, harbouring hundreds of cassettes and associated with the intI4 integrase gene, has recently been described in the small chromosome of Vibrio cholerae $[15,44,77]$. The $V$. cholerae small chromosome was found to contain an "integron island" consisting of clustered repeated sequences (VCRs) separated in most cases by a single ORF, organised in a similar way to the integron-borne gene cassette. Potential virulence genes (haemagglutinin and lipoproteins) have been identified as gene cassettes linked to VCRs in 
the $V$. cholerae integron island $[15,44,60]$. This complex integron structure constitutes a large pathogenicity island in the $V$. cholerae genome. Furthermore, this structure was found in Vibrio strains dating back to 1888 and predating the antibiotic era. It has been suggested that IntI 4 might be the ancestor of all the other integrases, which may have adapted to acquire antibiotic resistance genes only in the more recent past [60]. This hypothesis further supports the view that integrons may play a major role in accelerating bacterial evolution. Apart from drug resistance cassettes, virulence genes could also be disseminated by integrons thereby contributing to the evolution of bacterial virulence.

\subsection{Mobile gene cassettes}

The integron-borne gene cassettes confer resistance to many different antibiotics including aminoglycosides, cephalosporins, chloramphenicol, penicillins and trimethoprim, and for each of these antibiotic classes several distinct gene cassettes have been reported. Recently, a number of gene cassettes encoding extended-spectrum $\beta$-lactamases or carbapenemases have been described $\left(\right.$ bla $\left._{\mathrm{IMP}}, b l a_{\mathrm{VEB}-1}, b l a_{\mathrm{VIM}}\right)[2,49$, 50, 63, 69]. At least 15 different genes encoding aminoglycoside-adenyltransferases (aad) or aminoglycoside-acetyltransferases ( $a a c$ ) and conferring resistance to aminoglycosides - together with several different dihydrofolate-reductase genes $(d h f r)$ conferring resistance to trimethoprim - have been located as gene cassettes within integrons. Chloramphenicol resistance is frequently conferred by type B chloramphenicol acetyltransferase genes (catB) or by genes coding for one of the three known efflux pumps $(\mathrm{cml})$. Resistance genes to rifampicin (arr-2) and erythromycin (ereA) have also been described as gene cassettes within integrons. At least six ORFs of unknown functions have been described in naturally occurring integrons [10, 40, 59, 92].
The gene cassette is defined as a discrete unit consisting of one complete ORF followed by a recombination site, the 59-base element, also named attC (Fig. 1) [42, 73]. Each gene is associated at the 3 '-end with a particular 59-base element, which differs both in sequence and length although these elements are identifiable from common secondary structures. The attC site consists of a long inverted repeat sequence of variable length potentially forming an imperfect cruciform structure, which is flanked by inverse and forward core sequences (RYYYAAC is the consensus for the inverse sequence and GTTRRRY is the consensus for the forward sequence) [33].

Gene cassettes lack a promoter in front of the coding sequence and this implies that the promoter located in the 5'-CS of the integron is essential for the expression of the cassettes. In class 1 integrons the 5' -CS contains two potential promoters, $\mathrm{P}_{1}$ and $\mathrm{P}_{2}$. Four different $\mathrm{P}_{1}$ and two different $\mathrm{P}_{2}$ promoters have been described (Fig. 1) [20, 84]. An apparent polarisation of expression exists for $\mathrm{P}_{1}$ and $\mathrm{P}_{2}$, since the highest level of expression is obtained for the first cassette located directly downstream of the promoter. In contrast, distal gene cassettes are weakly expressed due to the premature transcription termination occurring within the 59-base element of the preceding gene cassettes [20].

Gene cassettes are considered as mobile elements, however they do not code for products involved in their own mobility [19]. In fact, gene cassettes exist free as covalently closed circular molecules generated by IntI-mediated excision of previously integrated cassettes from the same or another integron $[18,19,40]$. The circular intermediate participates in the IntI-mediated process of integration into the integron (Fig. 1).

Resistance genes harboured by resistant bacteria or by antibiotic-producing microorganisms could seem to be the main source of integron-derived gene cassettes. Integrons could "mop" up these genes following 
excision, and incorporate them into replicons, which could then be transferred among bacterial pathogens. Several pieces of evidence similarly support the hypothesis that housekeeping genes have evolved to modify antibiotics and that their recruitment could provide an alternate source of resistance genes [23, 68]. All resistance-encoding DNAs establish a resistance gene pool, which represents a potential source of gene cassettes incorporated into the integrons [28].

\subsection{Site-specific insertion of gene cassettes into the integron}

The site-specific insertion of gene cassettes into the variable region of integrons has been detected only in cells which express the integrase activity, indicating that this recombinase is required for the integration within the attI site [19,21]. A gene cassette available for integration is represented by a closed circular molecule formed by intI-mediated site-specific excision (Fig. 1) [18]. Cassettes are integrated predominantly at the attI site. Insertion should occur preferentially at the 5'-end of the first resident gene cassette.

The integrase interacts with both the primary recombination sites, that is the attI site located in the 5' -CS and the $a t t C$ site located at the 3'-end of each gene cassette. IntI strongly binds to four sites within the attI site $[36,37,74]$ and also weakly binds to the cassette-associated attC site [22].

Secondary target sites have been identified on natural plasmids and a mechanism for the recruitment of new genes to integron-borne gene cassettes has been postulated $[31,32,43]$. The secondary site in front of a gene not previously borne on cassettes may cause trapping of the gene by the integrase-mediated site-specific recombination between the attI and this secondary site. The formation of a complete cassette containing the new gene requires the acquisition of the $a t t C$ site probably through a further step of recombination from a pre-existing gene cassette [82]. This mechanism implies that almost any gene may become associated with integrons, although recombination with secondary sites is rare and less efficient when compared to recombination between primary sites.

\section{INTEGRON MOBILISATION}

In bacterial pathogens a variety of transposable elements have been identified and contribute to the evolution of the bacterial genome by excision and insertion of DNA fragments from a donor site, to other nonhomologous target sites. Transposons are mobile genetic elements which encode the necessary machinery to promote self-translocation (i.e. transposase and the DNA sites at which recombinase activity acts) [47, 83].

Some transposons are known to contribute to integron mobility. Class 1 and 2 integrons are often carried by $\operatorname{Tn} 21$ - and Tn7- transposable elements, respectively. Furthermore, some integrons have been identified in close proximity or juxtaposed with insertion sequences (IS) [71, 95]. It is evident that the association of a highly efficient gene-capture and expression system, together with the capacity for vertical and horizontal mobility, represents an important combination in the natural flux of resistance genes. Furthermore, integrons borne on transposons have been described as preferentially incorporated into conjugative plasmids, which then guarantees a broad-hostrange horizontal transfer of the resistance determinants.

\subsection{The Tn21 group of transposons}

$\operatorname{Tn} 21$ is a member of the $\operatorname{Tn} 3$ family of transposable elements, which is probably the most successful group of mobile DNA elements, found widely distributed in Gramnegative and Gram-positive bacteria [38, 53]. The Tn 21 transposon encodes genes 


\section{Transposon $\operatorname{Tn} 21$}

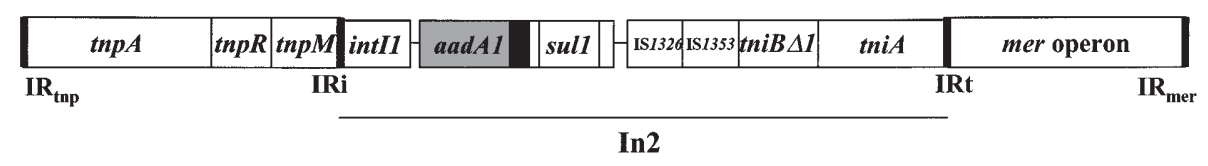

Figure 2. Schematic representation of the DNA structure of the Tn21 transposon (GenBank accession no. AF1413). White boxes represent the tnpA, tnpR and tnpM genes, the integrase gene (intI1), the sulfonamide resistance gene (sull), the putative integron transposition genes (tni), the IS1326 and IS1353 insertion sequences and the mer operon. The grey box represents the inserted gene cassette conferring resistance to streptomycin and spectinomicin (aadAl). The black box represents the attC site downstream of the aadAl gene cassette. Vertical bars indicate inverted repeats flanking the transposon ( $\mathrm{IR}_{\mathrm{tnp}}$ and $\left.\mathrm{IR}_{\mathrm{mer}}\right)$ and the In2 integron (IRi and IRt).

and sites required for transposition (including tnpA, tnpR, tnpM, res and IRs) (Fig. 2). In addition, $\operatorname{Tn} 21$ also encodes accessory genes that are primarily responsible for resistance to several classes of antibiotics. This transposon carries the mer operon and an integron called In2 $[38,53]$. The mer operon encodes enzymes that convert toxic mercuric ions into less toxic metallic mercury [62]. The In 2 integron is located between the mer operon and the transposition system. The latter integron also contains an aadA gene cassette, known to confer resistance to streptomycin and spectinomycin. In 2 is flanked by two 25 base pair inverted repeats (IRi, IRt) that suggest a potential mobility of In2. However, no evidence of self-transposability of the In 2 integron has been obtained to date.

Transposon Tn5090 (also named Tn402) of plasmid R751 was reported to contain a class 1 integron which harbours an intact $q a c E$ gene (this gene occurs in a deleted form in class 1 integrons and for this reason is designated qacE $\Delta 1$ ) but does not include the sull gene. This integron also encodes a complete set of transposition genes (tniA, tniB, tniQ, tniR) and may be a mobile ancestor of the In2 located in $\operatorname{Tn} 21$ (Fig. 2) [72]. Class 1 integrons including In0, In 2 and In 5 have been defined as defective transposon derivatives resulting from truncation of the transposition machinery following insertion of IS1326 and IS 1353 elements into the tniB gene (Fig. 2) [8, 53]. From the analysis of the structure of $\operatorname{Tn} 21$ and related transposons, a scheme describing the possible evolution and the relationship of several transposons has been developed $[53,72,96]$. It has been postulated that integrons were mobile elements which became inserted into a Tn21-ancestral mercury resistance transposon, possibly $\operatorname{Tn} 2613$ $[89,90]$ and whose transposition functions have been disrupted by multiple insertions of IS elements.

The occurrence of elements of the $\operatorname{Tn} 21$ subgroup in different strains and genera of bacteria is impressive: no other phylogenetically homogeneous group of transposons has such a variety of representative elements. Successful dissemination probably lies in the acquisition of the integrase system, which should confer a selective advantage for the diffusion of these elements.

In 1992, Zuhlsdorf and Wiedemann carried out a systematic investigation for the presence of the Tn21 group of transposons in a large collection of unselected clinical strains. They found that $19 \%$ of all strains in their collection showed a positive result for the presence of a $\operatorname{Tn} 21$ derivative. Furthermore, they showed that most of the strains contained the integrase gene although a great variety of defective transposons were 
described, with deletions in one or more of the transposition system genes [99].

An epidemiological study conducted in 1999 on genetic elements mediating multidrug resistance in pathogenic avian $E$. coli isolates concluded that more than half of the one hundred isolates examined carried a Tn21 transposon derivative [3]. Globally disseminated Tn21-like transposons are also found among commensal and environmental isolates [25, 98].

Reasons for the dissemination of $\operatorname{Tn} 21$ like transposons are currently unknown, but the fact that this kind of transposon has the potential to confer resistance against both older and newer antibiotics may be an important factor. Tn21 and its derivatives are major agents in the dissemination of mercury resistance in Gram-negative bacteria conferring resistance to both organic and inorganic mercuric compounds, used for the treatment of syphilis and in amalgam dental restorations, and particularly diffused in industrial waste contaminating soil and water [53]. At the same time these transposable elements confer resistance to various antibiotics through the resistance gene cassettes incorporated within the integron. The $\operatorname{Tn} 21$ gene cassette, aadA1, is one of the most prevalent resistance genes in the world and confers resistance to streptomycin. Nevertheless, this antibiotic is rarely used in modern human medicine, but in contrast is extensively used in animal husbandry as a therapeutic agent [13]. These observations suggest that Tn21 might have contributed to the dissemination of integrons, being positively selected in animal and human pathogens and in bacteria living in polluted environments.

\subsection{Clustering of resistance genes: is the multi-drug resistance encoded on antibiotic resistance islands?}

Clustering genes that confer resistance to different classes of antibiotics confers a selective advantage to the host, particularly when several antibiotics are simultaneously administered. The synergism between different resistance genes allows the recipient host to be positively selected by each individual class of antimicrobial agents. Furthermore, a genetic locus containing multiple resistance genes can be transferred en bloc to other genomes [51, 52].

Several examples describing the localisation of antibiotic resistance genes on plasmids or on the bacterial chromosome suggest that genes conferring multi-drug resistance can exist as complex configurations of physically linked elements. Each integron carrying a complex array of gene cassettes represents a cluster of physically and functionally associated resistance genes. In some cases integrons have been found associated with other resistance determinants leading to the assembly of larger genetic structures that are analogous to the well-defined pathogenicity islands. These structures could be considered as antibiotic resistance islands.

A well-known example of physical association of integrons with other resistance genes is present in the multi-drug resistant Salmonella enterica serovar Typhimurium, definitive type 104 (DT104). The majority of the DT104 isolates are resistant (R) to at least five drugs including ampicillin, chloramphenicol, streptomycin, sulphonamides and tetracycline (R-ACSSuT). All resistance genes responsible for the R-ACSSuT profile were identified within a pentaresistance genetic locus of a 10-kb XbaI DNA fragment, integrated in the $S$. enterica Typhimurium chromosome. In these isolates two class 1 integrons carrying the aadA2, pse-1 and sull genes, conferring resistance to streptomycin, $\beta$-lactams and sulphonamides, are located close together in the DT104 chromosome. The intervening region contains the characteristic flo $R_{s t}$ gene conferring resistance to florfenicol and chloramphenicol, along with the tet $R$ and tetA (class G) genes conferring tetracycline resistance (Fig. 3) [7, 80]. The complete 
A

DT104 pentaresistance gene cluster

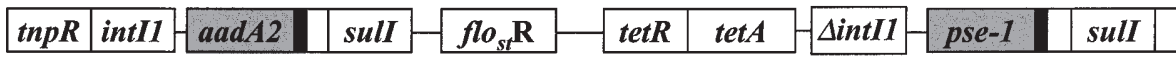

pSEM integron

\begin{tabular}{|l|l|l|l|l|l|l|l|l|}
\hline bla $_{\mathrm{SHV}-5}$ & IS26 & intI1 \\
\hline
\end{tabular} \begin{tabular}{|l|l|l|l|l|l|}
\hline \\
\hline
\end{tabular}

$\mathrm{C}$

pSAL-1 integron

\begin{tabular}{|l|l|l|l|l|l|l|l|l|l|l|l|l|l|}
\hline intII & ardA2 & sulI & ampR \\
\hline
\end{tabular}

Figure 3. Structural comparison of antibiotic resistance islands. Integron-borne gene cassettes are represented as grey boxes. Panel A: S. enterica serotype Typhimurium DT104 resistance gene cluster (GenBank accession no. AF071555). White boxes represent the putative resolvase gene (tnpR), the integrase gene (intI1), the sulfonamide resistance gene (sull), the florfenicol/chloramphenicol resistance gene $\left(f l o R_{s t}\right)$ and the tetracycline resistance genes (tet $R$ and tet $A$ ). The streptomycin resistance gene (aadA2) and the $\beta$-lactamase gene (pse-1) are integron-borne gene cassettes. Panel B: pSEM integron (EMBL accession nos. AJ009820 and AJ245670). White boxes represent the extendedspectrum $\beta$-lactamase gene (blaSHV-5), the insertion sequence (IS26), the integrase gene (intI1) and the sulfonamide resistance gene (sulI). The aminoglycoside-resistance genes (aacA4, aacCl and $a a d A 1)$ and ORFX and ORFX' are integron-borne gene cassettes. Panel C: pSAL-1 integron (EMBL accession no. AJ237702). White boxes represent the integrase gene (intI1), the sulfonamide resistance gene (sulI), the ORF341 and the extended-spectrum $\beta$-lactamase genes ( $\operatorname{ampC}$ and $\operatorname{ampR}$ ). The streptomycin resistance gene (aadA2) is the integron-borne gene cassette.

pentaresistance gene cluster is consistently absent in drug-sensitive isolates or in $S$. enterica Typhimurium isolates of other phage types exhibiting the same resistance profiles [75]. However, apparently similar clusters have recently been identified in nonDT104 isolates and in S. enterica serovar Agona, strongly suggesting a horizontal transfer of the pentaresistance gene cluster among Salmonella strains $[17,26]$. No experimental data in relation to the horizontal transfer of the resistance gene cluster has been reported so far. However, transduction experiments with a P22-like phage demonstrated a facilitated transduction of DT104 resistance to unrelated Salmonella recipient strains [81]. Furthermore, a putative resolvase gene, similar to $\operatorname{tnp} R$ of the Tn 3 transposons, has been identified adjacent to the intIl gene of the first integron in the DT104 pentaresistance gene cluster, suggesting that at least part of this complex structure might arise from a transposon (Chaslus-Dancla E., European Molecular Biology Laboratory (EMBL) accession no. AF121001).

Florfenicol was initially introduced as a therapeutic agent for the treatment of calf 
respiratory pasteurellosis and the floR resistance gene has been located on large conjugative plasmids in the fish pathogen Photobacterium damselae subsp. piscicida [46], and in clinical $E$. coli strains isolated from poultry and cattle $[16,45]$. These observations argue for an independent rapid spread of florfenicol resistance by horizontal transfer of the conjugative plasmid carrying the floR gene.

Another example of a putative antibiotic resistance island has recently been described on a broad-host-range plasmid pSEM, isolated from multiple-drug resistant strains of S. enterica Typhimurium [91, 95]. A class 1 integron conferring resistance to sulphonamides and aminoglycosides through the $a a c A 4, a a c C 1$ and aadAl gene cassettes was located near the $b l a_{\mathrm{SHV}-5}$ gene conferring resistance to extended-spectrum cephalosporins (Fig. 3). A very similar organisation of resistance genes was described on the plasmid pACM1 isolated from nosocomial strains of Klebsiella oxytoca $[70,71]$. An IS26 element was found juxtaposed to the 5' -CS of the integron that resulted in the deletion of the first 113 base pairs [95].

IS elements are a heterogeneous class of mobile elements, common to prokaryotic genomes, and capable of promoting their own translocation. These elements can bracket gene clusters forming composite transposons, where two flanking IS elements co-operate in mobilising the intervening DNA segment. These elements have also been involved in the assembling of genes in pathogenicity islands [55]. The physical association of the IS26 element with the bla $a_{\text {SHV-5 }}$ gene region and the integron could explain the formation of the antibiotic resistance island observed on the pSEM plasmid.

A complex resistance gene organisation was described in $S$. enterica serovar Enteritidis on the pSAL-1 plasmid conferring resistance to extended-spectrum cephalosporins by the presence of the bla $a_{\text {DHA-1 }} \beta$-lactamase. On pSAL-1, a class 1 integron carrying the aadA2 and sull genes was found juxtaposed to the $b l a_{\text {DHA-1 }}$ locus containing the $a m p C$ and $a m p R$ genes originating from the Morganella morganii chromosome, followed by a second non-functional copy of the sull gene (Fig. 3) [94]. This integron has unusual structures showing the partial duplication of the 3'CS, containing the ORF341, and carrying the $b l a$ DHA-1 locus integrated into a secondary recombination site, downstream of ORF341. A similar structure was previously described for two other integrons, In6 and In7 [41, 67, 85]. Besides containing ORF341, these integrons also carry a different array of resistance genes integrated at the $a t t I$ and at the secondary site downstream of ORF341. It has been postulated that the product of ORF341, whose function is yet unknown, might work as a novel recombinase preferentially recognising the secondary recombination site [94]. Moreover, the amino acid sequence deduced from ORF341 is similar to recently described putative transposases of Pseudomonas pseudoalcaligenes (EMBL accession no. AF028594) and E. coli (EMBL accession no. AF231986). These novel integrons, showing primary and secondary recombination sites, could play an important role in clustering multiple antibiotic resistance genes.

\section{INTEGRON EPIDEMIOLOGY}

Integrons are frequently reported in Gram-negative bacteria from patients with hospital-acquired infections or in strains responsible for nosocomial outbreaks (i.e. Pseudomonas aeruginosa, Klebsiella pneumoniae, E. coli, Citrobacter freundii, $K$. oxytoca, Enterobacter spp.) [34, 49, 50, 57, $58,63,69,70,92]$. A class 1 integron has also been found on a plasmid from Corynebacterium glutamicum [64].

Investigations of the role of integrons in resistant bacteria circulating in community have mainly been focused on the detection 
and characterisation of the pentaresistance locus found in the widely distributed S. enterica Typhimurium DT104 (see specific chapter on this issue [15']). Significant and recent investigations outlining the presence of integrons in zoonotic pathogens, such as Salmonella spp., E. coli and Campylobacter spp., are briefly summarised below.

Integrons in zoonotic pathogens. Epidemiologically unrelated multiple-drugresistant $S$. enterica Typhimurium strains isolated in 1997 in Albania showed an unusually wide-ranging resistance, conferred by the coexistence of three integrons in the same bacterial cell [91]. The three integrons, In-t 1, In- $\mathrm{t} 2$ and In-t 3 , were located on two different conjugative plasmids of the IncFI and IncL/M incompatibility group. Integrons conferred resistance to $\beta$-lactams, chloramphenicol, co-trimoxazole, and to the more commonly used aminoglycosides, including gentamicin and amikacin (conferred by the aadB, catB3, oxa1, aadA1, aacA 4 and aac $C 1$ gene cassettes, respectively). In-t 1 and In- $\mathrm{t} 2$ were both located on the IncFI plasmid, which has in the past been associated with the emergence of epidemic clones of multidrug-resistant Salmonella [1].

Molecular evidence supports the view that IncFI plasmids are evolving through sequential acquisition of integrons carrying different arrays of antibiotic-resistance genes. A 30-year retrospective investigation for the presence of integrons in both older and more recent IncFI plasmids provided evidence that In-t 2 , carried by a Tn21-derivative, was present in IncFI plasmids since the early 1970s while In-t1 represents a recent acquisition, being detected only on IncFI plasmids isolated in 1997 [11]. Moreover, an integron identical to In-t2, located on a large conjugative plasmid, has been reported in multi-drug resistant $S$. enterica Typhimurium strains isolated from finfish in India in 1999 [78].

The hypothesis that integrons may be responsible for the acquisition of most of the resistance genes in Salmonella spp. was confirmed by the molecular analysis of a collection of 333 resistant Salmonella strains representing the most frequent non-typhoidal serotypes, isolated between 1989 and 1998 in Spain [39]. The presence of class 1 integrons was identified in strains collected throughout the entire study period, being more frequent in serotypes Typhimurium, Ohio, Panama and Virchow. The aadAl and aadA2 cassettes (encoding streptomycinspectinomycin resistance), alone or in combination with other resistance genes, were found widely distributed in most of the Salmonella serotypes analysed. The pse-1 and $o x a-1$ genes, conferring resistance to $\beta$-lactams, the dhfrAl4 and dhfrAl genes, conferring resistance to trimethoprim, and the satl gene, conferring resistance to streptothricin, were also identified as gene cassettes within the variable region of integrons.

Molecular characterisation of antimicrobial resistance in $S$. enterica isolates from Ireland and France also reported the presence of multiple integrons in strains obtained from human, animal and food sources [12, 27]. These integrons preferentially carried one or two of the pse-1, aadA2, aadA1 and dhfrAl gene cassettes confirming descriptions reported for the Spanish Salmonella.

The role of integrons in the dissemination of antibiotic resistance has also been investigated in $E$. coli strains isolated from humans and animals. The ECOR collection, a widely used set of 72 reference $E$. coli strains isolated between 1973 and 1983 from a variety of healthy human and animal hosts [65] has also been tested for the presence of integrons. Four strains from this collection were found positive for a class 1 integron. In three strains the integron was associated with the presence of the Tn 21 transposon, while the fourth strain contained the novel aadA7 gene cassette [61]. The presence of the $\operatorname{Tn} 21$ transposon, and consequently of the integron In 2 in E. coli strains of this collection, can be traced back to 1973 . 
The occurrence of integrons in aminoglycoside resistant $E$. coli of porcine and bovine origin from Denmark has recently been reported [79]. This investigation revealed that integrons carrying the gentamicin resistance $a a d B$ gene are frequently found in bovine $E$. coli isolated in this country. Since the gentamicin treatment of cattle or calves has never been approved in Denmark it is likely that the horizontal transfer of integrons caused gentamicin resistance in E. coli.

Integrons conferring resistance to streptomycin, trimethoprim and $\beta$-lactams have also been documented in multiresistant $E$. coli isolates from the normal intestinal flora of healthy fattening pigs [86]. Large transmissible plasmids containing integrons were detected in several of these isolates, indicating that the enteric commensals of domestic animals may act as reservoir of antibiotic resistance genes.

Finally, novel integron-like structures have been detected in a collection of Irish thermophilic Campylobacter spp. cultured from clinical cases of gastroenteritis and from porcine and poultry sources [54]. Interestingly, the gene cassettes harboured by these integron-like structures did not match any known DNA sequences.

Campylobacter spp. shows the natural ability for transformation and interspecies transfer of DNA, including resistance genes [35], and the existence of integron-like structures in the genome could explain the incorporation of unrelated DNA, frequently observed in this species. Integron-mediated site-specific recombination may have interesting implications in understanding genome evolution in Campylobacter spp.

\section{CONCLUSION}

The indiscriminate usage of antibiotics in human medicine and animal husbandry promotes the spread of multiple antibiotic resistance. Recent advances in the study of antibiotic resistance have led to the discovery of molecular mechanisms for the acquisition of resistance genes by integron-mediated recombination.

Integrons have been involved in the recruitment and expression of resistance genes and have been found widely distributed among resistant bacteria circulating in hospitals and in the community. Their presence in bacterial genomes can be traced back several years.

Integrons should be regarded as the major means of short-term accumulation of resistance determinants in bacterial genome. Furthermore, their role in the capture of genes is particularly important when associated with horizontal transfer of the resistance determinant, mobilised by broad-host-range conjugative plasmids. The association of integrons with mobile elements promotes their vertical transmission from plasmids to the bacterial chromosome and among different replicons, contributing to the dissemination of resistance genes.

The evolution of multi-drug resistance seems to proceed unrelentingly through the acquisition and clustering of dispersed resistance genes by integrons. Controlling this process in the bacteria represents a significant challenge to public health.

\section{ACKNOWLEDGMENTS}

I am very grateful to Séamus Fanning, Stefan Schwarz, Fabio Tosini, Ida Luzzi and Paolo Visca for helpful suggestions and constructive discussions, and to Luca Busani and Giovanni Pezzotti for the critical reading of the manuscript. I wish to thank Emma Filetici, Susanna Mariotti, Cristina Pezzella and Laura Villa for their expert collaboration in the studies mentioned in this review.

\section{REFERENCES}

[1] Anderson E.S., Threlfall E.J., Carr J.M., McConnell M.M., Smith H.R., Clonal distribution of resistance plasmid-carrying Salmonella typhimurium, mainly in the Middle East, J. Hyg. (Lond.) 79 (1977) 425-448. 
[2] Arakawa Y., Murakami M., Suzuki K., Ito H., Wacharotayankun R., Ohsuka S., Kato N., Ohta M., A novel integron-like element carrying the metallo-beta-lactamase gene $b l a_{\text {IMP }}$, Antimicrob. Agents Chemother. 39 (1995) 1612-1615.

[3] Bass L., Liebert C.A., Lee M.D., Summers A.O., White D.G., Thayer S.G., Maurer J.J., Incidence and characterization of integrons, genetic elements mediating multiple-drug resistance, in avian Escherichia coli, Antimicrob. Agents Chemother. 43 (1999) 2925-2929.

[4] Baur B., Hanselmann K., Schlimme W., Jenni B., Genetic transformation in freshwater: Escherichia coli is able to develop natural competence, Appl. Environ. Microbiol. 62 (1996) 3673-3678.

[5] Belogurov A.A., Delver E.P., Rodzevich O.V., Plasmid pKM101 encodes two nonhomologous antirestriction proteins (ArdA and ArdB) whose expression is controlled by homologous regulatory sequences, J. Bacteriol. 175 (1993) 4843-4850.

[6] Bissonnette L., Roy P.H., Characterization of In0 of Pseudomonas aeruginosa plasmid pVS1, an ancestor of integrons of multiresistance plasmids and transposons of Gram-negative bacteria, J. Bacteriol. 174 (1992) 1248-1257.

[7] Briggs C.E., Fratamico P.M., Molecular characterization of an antibiotic resistance gene cluster of Salmonella typhimurium DT104, Antimicrob. Agents Chemother. 43 (1999) 846-849.

[8] Brown H.J., Stokes H.W., Hall R.M., The integrons In0, In2, and In5 are defective transposon derivatives, J. Bacteriol. 178 (1996) 4429-4437.

[9] Brunel F., Davison J., Restriction insensitivity in bacteriophage T5 III. Characterization of EcoRIsensitive mutants by restriction analysis, J. Mol. Biol. 15 (1979) 527-543.

[10] Bunny K.L., Hall R.M., Stokes H.W., New mobile gene cassettes containing an aminoglycoside resistance gene, aacA7, and a chloramphenicol resistance gene, catB3, in an integron in pBWH301, Antimicrob. Agents Chemother. 39 (1995) 686-693.

[11] Carattoli A., Villa L., Pezzella C., Bordi E., Visca P., Expanding drug-resistance through integron acquisition by IncFI plasmids of Salmonella enterica serotype Typhimurium, Emerg. Infect. Dis. (in press).

[12] Casin I., Breuil J., Brisabois A., Moury F., Grimont F., Collatz E., Multidrug-resistant human and animal Salmonella typhimurium isolates in France belong predominantly to a DT104 clone with the chromosome- and integron-encoded betalactamase PSE-1, J. Infect. Dis. 179 (1999) 11731182

[13] Chiew Y.F., Yeo S.F., Hall L.M., Livermore D.M., Can susceptibility to an antimicrobial be restored by halting its use? The case of streptomycin versus Enterobacteriaceae, J. Antimicrob. Chemother. 41 (1998) 247-251.
[14] Chilley P.M., Wilkins B.M., Distribution of the $\operatorname{ardA}$ family of antirestriction genes on conjugative plasmids, Microbiology 141 (1995) 21572164.

[15] Clark C.A., Purins L., Kaewrakon P., Manning P.A., VCR repetitive sequence elements in the Vibrio cholerae chromosome constitute a megaintegron, Mol. Microbiol. 26 (1997) 1137-1138.

[15'] Cloeckaert A., Schwarz S., Molecular characterization, spread and evolution of multidrug resistance in Salmonella enterica Typhimurium DT104, Vet. Res. 32 (2001) 301-310.

[16] Cloeckaert A., Baucheron S., Flaujac G., Schwarz S., Kehrenberg C., Martel J.L., Chaslus-Dancla E., Plasmid-mediated florfenicol resistance encoded by the floR gene in Escherichia coli isolated from cattle, Antimicrob. Agents Chemother. 44 (2000) 2858-2860.

[17] Cloeckaert A., Sidi Boumedine K., Flaujac G., Imberechts H., D'Hooghe I., Chaslus-Dancla E., Occurrence of a Salmonella enterica serovar Typhimurium DT104-like antibiotic resistance gene cluster including the floR gene in $S$. enterica serovar Agona, Antimicrob. Agents Chemother. 44 (2000) 1359-1361.

[18] Collis C.M., Hall R.M., Gene cassettes from the insert region of integrons are excised as covalently closed circles, Mol. Microbiol. 6 (1992) 2875-2885.

[19] Collis C.M., Hall R.M., Site-specific deletion and rearrangement of integron insert genes catalyzed by the integron DNA integrase, J. Bacteriol. 174 (1992) 1574-1585.

[20] Collis C.M., Hall R.M., Expression of antibiotic resistance genes in the integrated cassettes of integrons, Antimicrob. Agents Chemother. 39 (1995) 155-162.

[21] Collis C.M., Grammaticopoulos G., Briton J., Stokes H.W., Hall R.M., Site-specific insertion of gene cassettes into integrons, Mol. Microbiol. 9 (1993) 41-52.

[22] Collis C.M., Kim M.J., Stokes H.W., Hall R.M., Binding of the purified integron DNA integrase Int11 to integron- and cassette-associated recombination sites, Mol. Microbiol. 29 (1998) 477490.

[23] Costa Y., Galimand M., Leclercq R., Duval J., Courvalin P., Characterization of the chromosomal aac(6')-Ii gene specific for Enterococcus faecium, Antimicrob. Agents Chemother. 37 (1993) 1896-1903.

[24] Courvalin P., The Garrod Lecture. Evasion of antibiotic action by bacteria, J. Antimicrob. Chemother. 37 (1996) 855-869.

[25] Dahlberg C., Hermansson M., Abundance of Tn3, $\operatorname{Tn} 21$, and $\operatorname{Tn} 501$ transposase (tnpA) sequences in bacterial community DNA from marine environments, Appl. Environ. Microbiol. 61 (1995) 3051-3056.

[26] Daly M., Fanning S., Characterization and chromosomal mapping of antimicrobial resistance 
genes in Salmonella enterica serotype Typhimurium, Appl. Environ. Microbiol. 66 (2000) 4842-4848

[27] Daly M., Buckley J., Power E., O'Hare C., Cormican M., Cryan B., Wall P.G., Fanning S., Molecular characterization of Irish Salmonella enterica serotype Typhimurium: detection of class I integrons and assessment of genetic relationships by DNA amplification fingerprinting, Appl. Environ. Microbiol. 66 (2000) 614-619.

[28] Davies J., Inactivation of antibiotic and the dissemination of resistance genes, Science 264 (1994) 375-382.

[29] Davison J., Genetic exchange between bacteria in the environment, Plasmid 42 (1999) 73-91.

[30] de la Cruz I., Davies I., Horizontal gene transfer and the origin of species: lessons from bacteria, Trends Microbiol. 8 (2000) 128-133.

[31] Francia M.V., Garcia Lobo J.M., Gene integration in the Escherichia coli chromosome mediated by Tn21 integrase (Int21), J. Bacteriol. 178 (1996) 894-889.

[32] Francia M.V., de la Cruz F., Garcia Lobo J.M., Secondary-sites for integration mediated by the Tn21 integrase, Mol. Microbiol. 10 (1993) 823-

[33] Francia M.V., Avila P., de la Cruz F., Garcia Lobo J.M., A hot spot in plasmid F for sitespecific recombination mediated by $\operatorname{Tn} 21$ integron integrase, J. Bacteriol. 179 (1997) 4419-4425.

[34] Giakkoupi P., Tzouvelekis L.S., Tsakris A., Loukova V., Sofianou D., Tzelepi E., IBC-1, a novel integron-associated class A beta-lactamase with extended-spectrum properties produced by an Enterobacter cloacae clinical strain, Antimicrob. Agents Chemother. 44 (2000) 2247-2253.

[35] Gibreel A., Skold O., High-level resistance to trimethoprim in clinical isolates of Campylobacter jejuni by acquisition of foreign genes $(d f r l$ and $d f r 9$ ) expressing drug-insensitive dihydrofolate reductases, Antimicrob. Agents Chemother. 42 (1998) 3059-3064.

[36] Gravel A., Fournier B., Roy P.H., DNA complexes obtained with the integron integrase IntI1 at the attI1 site, Nucleic Acids Res. 26 (1998) 4347-4355.

[37] Gravel A., Messier N., Roy P.H., Point mutations in the integron integrase IntI1 that affect recombination and/or substrate recognition, J. Bacteriol. 180 (1998) 5437-5442.

[38] Grinsted J., de la Cruz F., Schmitt R., The Tn21 subgroup of bacterial transposable elements, Plasmid 24 (1990) 163-189.

[39] Guerra B., Soto S., Cal S., Mendoza M.C., Antimicrobial resistance and spread of class 1 integrons among Salmonella serotypes, Antimicrob. Agents Chemother. 44 (2000) 2166-2169.

[40] Hall R.M., Collis C.M., Mobile gene cassettes and integrons: capture and spread of genes by site-specific recombination, Mol. Microbiol. 15 (1995) 593-600

[41] Hall R.M., Stokes H.W., The structure of a partial duplication in the integron of plasmid pDGO100, Plasmid 23 (1990) 76-79.

[42] Hall R.M., Brookes D.E., Stokes H.W., Sitespecific insertion of genes into integrons: role of the 59-base element and determination of the recombination cross-over point, Mol. Microbiol. 5 (1991) 1941-1959.

[43] Hansson K., Skold O., Sundstrom L., Nonpalindromic attl sites of integrons are capable of site-specific recombination with one another and with secondary targets, Mol. Microbiol. 26 (1997) 441-453.

[44] Heidelberg J.F., Eisen J.A., Nelson W.C., Clayton R.A., Gwinn M.L., Dodson R.J., Haft D.H., Hickey E.K., Peterson J.D., Umayam L., Gill S.R., Nelson K.E., Read T.D., Tettelin H., Richardson D., Ermolaeva M.D., Vamathevan J., Bass S., Qin H., Dragoi I., Sellers P., McDonald L., Utterback T., Fleishmann R.D., Nierman W.C., White O., DNA sequence of both chromosomes of the cholera pathogen Vibrio cholerae, Nature 406 (2000) 477-483.

[45] Keyes K., Hudson C., Maurer J.J., Thayer S., White D.G., Lee M.D., Detection of florfenicol resistance genes in Escherichia coli isolated from sick chickens, Antimicrob. Agents Chemother. 44 (2000) 421-424.

[46] Kim E., Aoki T., Sequence analysis of the florfenicol resistance gene encoded in the transferable R-plasmid of a fish pathogen, Pasteurella piscicida, Microbiol. Immunol. 40 (1996) 665669

[47] Kleckner N., Transposable elements in prokaryotes, Annu. Rev. Genet. 15 (1981) 341-404.

[48] Klemm M., Cheng C., Cassell G., Shuman S., Segall A.M., Peptide inhibitors of DNA cleavage by tyrosine recombinases and topoisomerases, J. Mol. Biol. 23 (2000) 1203-1216.

[49] Laraki N., Galleni M., Thamm I., Riccio M.L., Amicosante G., Frère J.M., Rossolini G.M., Structure of In31, a bla $\mathrm{IMP}_{\text {-containing Pseudomonas }}$ aeruginosa integron phyletically related to In5, which carries an unusual array of gene cassettes, Antimicrob. Agents Chemother. 43 (1999) 890901.

[50] Lauretti L., Riccio M.L., Mazzariol A., Cornaglia G., Amicosante G., Fontana R., Rossolini G.M., Cloning and characterization of bla $a_{\mathrm{VIM}}$, a new integron-borne metallo-beta-lactamase gene from a Pseudomonas aeruginosa clinical isolate, Antimicrob. Agents Chemother. 43 (1999) 15841590 .

[51] Lawrence J.G., Selfish operons and speciation by gene transfer, Trends Microbiol. 5 (1997) 355359 .

[52] Lawrence J.G., Selfish operons: the evolutionary impact of gene clustering in prokaryotes and 
eukaryotes, Curr. Opin. Genet. Dev. 9 (1999) 642-648.

[53] Liebert C.A., Hall R.M., Summers A.O., Transposon Tn21, flagship of the floating genome, Microbiol. Mol. Biol. Rev. 63 (1999) 507-522.

[54] Lucey B., Crowley D., Moloney P., Cryan B., Daly M., O'Halloran F., Threlfall E.J., Fanning S., Integronlike structures in Campylobacter spp. of human and animal origin, Emerg. Infect. Dis. 6 (2000) 50-55

[55] Mahillon J., Leonard C., Chandler M., IS elements as constituents of bacterial genomes, Res. Microbiol. 150 (1999) 675-687.

[56] Martinez E., de la Cruz F., Genetic elements involved in Tn21 site-specific integration, a novel mechanism for the dissemination of antibiotic resistance genes, EMBO J. 9 (1990) 1275-1281.

[57] Martinez-Freijo P., Fluit A.C., Schmitz F.J., Grek V.S., Verhoef J., Jones M.E., Class I integrons in Gram-negative isolates from different European hospitals and association with decreased susceptibility to multiple antibiotic compounds, J. Antimicrob Chemother. 42 (1998) 689-696.

[58] Martinez-Freijo P., Fluit A.C., Schmitz F.J., Verhoef J., Jones M.E., Many class I integrons comprise distinct stable structures occurring in different species of Enterobacteriaceae isolated from widespread geographic regions in Europe, Antimicrob. Agents Chemother. 43 (1999) 686689.

[59] Mazel D., Davies J., Antibiotic resistance. The big picture, Adv. Exp. Med. Biol. 456 (1998) 1-6.

[60] Mazel D., Dychinco B., Webb V.A., Davies J., A distinctive class of integron in the Vibrio cholerae genome, Science 280 (1998) 605-608.

[61] Mazel D., Dychinco B., Webb V.A., Davies J., Antibiotic resistance in the ECOR collection: integrons and identification of a novel aad gene, Antimicrob. Agents Chemother. 44 (2000) 15681574.

[62] Misra T.K., Bacterial resistances to inorganic mercury salts and organomercurials, Plasmid 27 (1992) 4-16.

[63] Naas T., Poirel L., Karim A., Nordmann P., Molecular characterization of In50, a class 1 integron encoding the gene for the extended-spectrum beta-lactamase VEB-1 in Pseudomonas aeruginosa, FEMS Microbiol. Lett.176 (1999) 411-419.

[64] Nesvera J., Hochmannova J., Patek M., An integron of class 1 is present on the plasmid pCG4 from Gram-positive bacterium Corynebacterium glutamicum, FEMS Microbiol Lett. 169 (1998) 391-395.

[65] Ochman H., Selander R.K., Standard reference strains of Escherichia coli from natural populations, J. Bacteriol. 157 (1984) 690-693.

[66] Ochman H., Lawrence J.G., Groisman E.A., Lateral gene transfer and the nature of bacterial innovation, Nature 405 (2000) 299-304.
[67] Parsons Y., Hall R.M., Stokes H.W., A new trimethoprim resistance gene, $d h f r X$, in the $\operatorname{In} 7$ integron of plasmid pDGO100, Antimicrob. Agents Chemother. 35 (1991) 2436-2439.

[68] Payie K.G., Clarke A.J., Characterization of gentamicin 2'-N-acetyltransferase from Providencia stuartii: its use of peptidoglycan metabolites for acetylation of both aminoglycosides and peptidoglycan, J. Bacteriol. 179 (1997) 4106-4114.

[69] Poirel L., Naas T., Guibert M., Chaibi E.B., Labia R., Nordmann P., Molecular and biochemical characterization of VEB-1, a novel class A extended-spectrum beta-lactamase encoded by an Escherichia coli integron gene, Antimicrob. Agents Chemother. 43 (1999) 573-581.

[70] Preston K.E., Kacica M.A., Limberger R.J., Archinal W.A., Venezia R.A., The resistance and integrase genes of pACM1, a conjugative multiple-resistance plasmid, from Klebsiella oxytoca, Plasmid 37 (1997) 105-118.

[71] Preston K.E., Radomski C.C.A., Venezia R.A., The cassettes and 3' conserved segment of an integron from Klebsiella oxytoca plasmid pACM1, Plasmid 42 (1999) 104-114.

[72] Radstrom P., Skold O., Swedberg G., Flensburg J., Roy P.H., Sundstrom L., Transposon Tn5090 of plasmid R751, which carries an integron, is related to $\mathrm{Tn} 7, \mathrm{Mu}$, and the retroelements, $\mathrm{J}$. Bacteriol. 176 (1994) 3257-3268.

[73] Recchia G.D., Hall R.M., Gene cassettes: a new class of mobile element, Microbiology 141 (1995) 3015-3027.

[74] Recchia G.D., Stokes H.W., Hall R.M., Characterisation of specific and secondary recombination sites recognised by the integron DNA integrase, Nucleic Acids Res. 22 (1994) 2071-2078.

[75] Ridley A., Threlfall E.J., Molecular epidemiology of antibiotic resistance genes in multiresistant epidemic Salmonella typhimurium DT104, Microb. Drug. Resist. 4 (1998) 113-118.

[76] Rouch D.A., Cram D.S., DiBerardino D., Littlejohn T.G., Skurray R.A., Efflux-mediated antiseptic resistance gene qacA from Staphylococcus aureus: common ancestry with tetracycline- and sugar-transport proteins, Mol. Microbiol. 4 (1990) 2051-2062.

[77] Rowe-Magnus D.A., Guerout A.M., Mazel D., Super-integrons, Res. Microbiol. 150 (1999) 641651

[78] Ruiz J., Capitano L., Nunez L., Castro D., Sierra J.M., Hatha M., Borrego J.J., Vila J., Mechanisms of resistance to ampicillin, chloramphenicol and quinolones in multiresistant Salmonella typhimurium strains isolated from fish, J. Antimicrob. Chemother. 43 (1999) 699-702.

[79] Sandvang D., Aarestrup F.M., Characterization of aminoglycoside resistance genes and class 1 integrons in porcine and bovine gentamicinresistant Escherichia coli, Microb. Drug Resist. 6 (2000) 19-27. 
[80] Sandvang D., Aarestrup F.M., Jensen L.B., Characterisation of integrons and antibiotic resistance genes in Danish multiresistant Salmonella enterica Typhimurium DT104, FEMS Microbiol. Lett. 157 (1997) 177-181.

[81] Schmieger H., Schicklmaier P., Transduction of multiple drug resistance of Salmonella enterica serovar Typhimurium DT104, FEMS Microbiol. Lett. 170 (1999) 251-256.

[82] Segal H., Francia M.V., Lobo J.M., Elisha G., Reconstruction of an active integron recombination site after integration of a gene cassette at a secondary site, Antimicrob. Agents Chemother. 43 (1999) 2538-2541.

[83] Stellwagen A.E., Craig N.L., Mobile DNA elements: controlling transposition with ATP-dependent molecular switches, Trends Biochem. Sci. 23 (1998) 486-490.

[84] Stokes H.W., Hall R.M., A novel family of potentially mobile DNA elements encoding sitespecific gene-integration functions: integrons, Mol. Microbiol. 3 (1989) 1669-1683.

[85] Stokes H.W., Tomaras C., Parsons Y., Hall R.M., The partial 3'-conserved segment duplications in the integrons In6 from $\mathrm{pSa}$ and In 7 from pDGO100 have a common origin, Plasmid 30 (1993) 39-50.

[86] Sunde M., Sorum H., Characterization of integrons in Escherichia coli of the normal intestinal flora of swine, Microb. Drug Resist. 5 (1999) 279-287.

[87] Sundstrom L., The potential of integrons and connected programmed rearrangements for mediating horizontal gene transfer, APMIS 84 (1998) 3742.

[88] Sundstrom L., Skold O., The dhfrI trimethoprim resistance gene of $\mathrm{Tn} 7$ can be found at specific sites in other genetic surroundings, Antimicrob. Agents Chemother. 34 (1990) 642-650.

[89] Tanaka M., Yamamoto T., Sawai T., Evolution of complex resistance transposons from an ancestral mercury transposon, J. Bacteriol. 153 (1983) 1432-1438.

[90] Tanaka M., Yamamoto T., Sawai T., Fine structure of transposition genes on Tn2603 and complementation of its tnpA and tnpR mutations by related transposons, Mol. Gen. Genet. 191 (1983) 442-450.

[91] Tosini F., Visca P., Luzzi I., Dionisi A.M., Pezzella C., Petrucca A., Carattoli A., Class 1 integron-borne multiple-antibiotic resistance carried by IncFI and IncL/M plasmids in Salmonella enterica serotype Typhimurium, Antimicrob. Agents Chemother. 42 (1998) 3053-3058.

[92] Tribuddharat C., Fennewald M., Integronmediated rifampin resistance in Pseudomonas aeruginosa, Antimicrob. Agents Chemother. 43 (1999) 960-962.

[93] Trieu-Cuot P., Courvalin P., Evolution and transfer of aminoglycoside resistance genes under natural conditions, J. Antimicrob. Chemother. 18 (1986) 93-102.

[94] Verdet C., Arlet G., Barnaud G., Lagrange P.H., Philippon A., A novel integron in Salmonella enterica serovar Enteritidis, carrying the bla(DHA-1) gene and its regulator gene $a m p R$, originated from Morganella morganii, Antimicrob. Agents Chemother. 44 (2000) 222-225.

[95] Villa L., Pezzella C., Tosini F., Visca P., Petrucca A., Carattoli A., Multiple-antibiotic resistance mediated by structurally related IncL/M plasmids carrying an extended-spectrum beta-lactamase gene and a class 1 integron, Antimicrob. Agents Chemother. 44 (2000) 2911-2914.

[96] Wiedemann B., Meyer J.F., Zuhlsdorf M.T., Insertions of resistance genes into Tn21-like transposons, J. Antimicrob. Chemother. 18 (1986) 8592.

[97] Wilkins B.M., Chilley P.M., Thomas A.T., Pocklington M.J., Distribution of restriction enzyme recognition sequences on broad host range plasmid RP4: molecular and evolutionary implications, J. Mol. Biol. 258 (1996) 447-456.

[98] Wireman J., Liebert C.A., Smith T., Summers A.O., Association of mercury resistance with antibiotic resistance in the Gram-negative fecal bacteria of primates, Appl. Environ. Microbiol. 63 (1997) 4494-4503.

[99] Zuhlsdorf M.T., Wiedemann B., Tn21-specific structures in Gram-negative bacteria from clinical isolates, Antimicrob. Agents Chemother. 36 (1992) 1915-1921. 